\title{
Flowering of Sugarcane Genotypes under Different Artificial Photoperiod Conditions
}

\author{
Maria Letícia G. Melloni', Maria Natália G. Melloni' ${ }^{1}$, Maximiliano S. Scarpari², \\ Júlio César Garcia², Marcos G. A. Landell1, Luciana R. Pinto1* \\ ${ }^{1}$ Faculdade de Ciências Agrárias e Veterinárias, Universidade Estadual Paulista, Jaboticabal, Brazil \\ ${ }^{2}$ Sugarcane Research Center, Instituto Agronômico de Campinas (IAC), Ribeirão Preto, Brazil \\ Email: ${ }^{*}$ lurossini@iac.sp.gov.br
}

Received 17 December 2014; accepted 15 February 2015; published 25 February 2015

Copyright (C) 2015 by authors and Scientific Research Publishing Inc.

This work is licensed under the Creative Commons Attribution International License (CC BY). http://creativecommons.org/licenses/by/4.0/

(c) (i) Open Access

\begin{abstract}
Flowering is essential in any breeding programme, particularly in genetic introgression programmes in which flowering synchronism is required. In this work, 16 sugarcane genotypes were evaluated using three different flowering-inductive photoperiod treatments $(30 \mathrm{~s}, 45 \mathrm{~s}$, and 1 min of a daily photoperiod decrease from $12 \mathrm{~h} 55$ of light). Each genotype was planted in $43 \mathrm{~L}$ pots (equal proportion of soil, sand, and substrate) with three tillers per pot. Plants with 4 to 6 internodes were placed in a photoperiod facility with three controlled chambers, each chamber containing all 16 genotypes (one treatment per chamber). The temperature range $\left(21^{\circ} \mathrm{C}\right.$ to $\left.32^{\circ} \mathrm{C}\right)$ and humidity were the same for all of the treatments. The flower induction started in September 2010 and ended in April 2011. The plant elongation and flag leaf and inflorescence emergence were recorded and the pollen viability was evaluated by using the iodine staining method. The photoperiod facility provided suitable conditions for flowering, as the plants in the three treatments successfully flowered. The genotypes in the three treatments behaved differently in relation to the date of panicle emergence, with the treatment of $45 \mathrm{~s}$ showing better results. The results here presented contribute to synchronise flowering for desired sugarcane crosses, particularly those from introgression programmes between commercial cultivars and species from the Saccharum complex.
\end{abstract}

\section{Keywords}

Artificial Induction, Leaf Flag, Photoperiod Facilities, Physiologic Flowering, Pollen

\footnotetext{
${ }^{*}$ Corresponding author.
}

How to cite this paper: Melloni, M.L.G., Melloni, M.N.G., Scarpari, M.S., Garcia, J.C., Landell, M.G.A. and Pinto, L.R. (2015) Flowering of Sugarcane Genotypes under Different Artificial Photoperiod Conditions. American Journal of Plant Sciences, 6, 456-463. http://dx.doi.org/10.4236/ajps.2015.63051 


\section{Introduction}

In Brazil, sugarcane crosses have been performed under natural conditions in the Northeast coastal region, which has ideal climate conditions for floral induction. However, sugarcane breeders have found difficulties in synchronising flowering in specific crosses, such as those between commercial cultivars and Saccharum spontaneum to broaden the genetic base of sugarcane and to increase the fibre content and biomass.

The process of inflorescence formation is difficult to define because it depends on the genotype, weather and changes that occur during the growing season. The flowering stimulus occurs during 18 - 25 days ([1]); in the Southern Hemisphere, the meristem differentiation for inflorescence formation occurs in February, March and April, and flowering occurs in April, May and June ([2] [3]).

Among the external factors that influence flowering induction, photoperiod is of high importance. Although sugarcane behaves as a short-day plant, successive long nights are also required to induce flowering ([4]). The ideal day length for flowering appears to be approximately $12 \mathrm{~h} 55 \mathrm{~min}$ and constitutes the day length adopted for most of the sugarcane cultivars grown worldwide ([5] [6]). Even at locations where the inductive photoperiod conditions occur, the emergence of inflorescences may not be uniform, revealing that the temperature is also important for flowering ([7]). It is believed that the minimum temperature rarely falls below $18^{\circ} \mathrm{C}$ and the maximum never exceed $32^{\circ} \mathrm{C}$ in areas with abundant flowering ([6] [8]). Moreover, temperatures below $21^{\circ} \mathrm{C}$ can delay growth and panicle emergence ([1]). The pollen grain viability is also affected by the temperature, mainly cold temperatures, resulting in pollen grains that are unviable; in fact, night temperatures below $15^{\circ} \mathrm{C}$ before or during flowering may cause anther abortion and male sterility ([5]).

Another important factor that affects sugarcane flowering is the soil moisture, which can interfere with tassel formation, as a water deficit during the inductive period can delay flowering. Indeed, a lack of water inhibits the translocation of photoassimilates to the apex, and therefore elongation of the inflorescence peduncle and anthers exposure ([9]).

Photoperiod management in areas of unfavourable natural conditions of flowering can be conducted by using photoperiod facilities. Controlled temperatures have been adopted by some sugarcane breeding programmes in Australia, South Africa and the USA to synchronise panicle emergence among desirable cultivars. In Brazil, the first fully automated photoperiod facility capable of simulating the ideal conditions of temperature and photoperiod to induce sugarcane flowering was built at the Campinas Agronomic Institute (IAC)—Sugarcane Center, which is an unfavourable site for natural sugarcane flowering ([10]).

Due to the instability of sugarcane flowering and pollen viability in São Paulo State, techniques that artificially synchronise flowering and maintain pollen viability have a great impact on sugarcane breeding programmes. Moreover, the inductive photoperiod of the Brazilian sugarcane genotypes is still unknown mainly due to a lack of studies related to flowering induction at photoperiod facilities. Therefore, the present study aimed to study the behaviour of 16 sugarcane genotypes using different inductive flowering photoperiod treatments. The results will contribute to synchronise flowering to planning crosses and also help breeders in genetic introgression programmes between commercial sugarcane cultivars and wild sugarcane species, especially those from Saccharum spontaneum.

\section{Methods}

\subsection{Material}

The experiment was conducted at the IAC—Sugarcane Center at Ribeirão Preto, São Paulo State in the period of September 2010 to April 2011. Sixteen sugarcane genotypes (Table 1) with high sucrose and fibre contents were evaluated for flowering induction under different artificial photoperiod conditions.

\subsection{Experimental Design}

The 16 sugarcane genotypes were planted in pots of $43 \mathrm{~L}$ with equal amounts of clay soil, sand and substrate $\left(\right.$ Plantmax $^{\circledR}$ ), with the recommended fertilisation, maintaining three tillers of each genotype per pot. The pots were placed randomly on three mobile wagons in separate chambers with controlled photoperiods (Figure 1). Induction began when the genotypes had 4 to 6 well-formed internodes to ensure maturity for flowering ([1]). 
Table 1. Sugarcane genotypes evaluated for flowering inductive photoperiod.

\begin{tabular}{llcc}
\hline & \multicolumn{2}{c}{ Genotypes } & \\
\hline IACSP94-2101 & IACSP00-8206 & CTC12 & SP89-1115 \\
IACSP93-2060 & IACSP97-2055 & CTC8 & SP90-1638 \\
IACSP96-7569 & IACSP95-5094 & CTC6 & SP80-1842 \\
IACSP00-8095 & CO213 & CTC15 & RB867515 \\
\hline
\end{tabular}

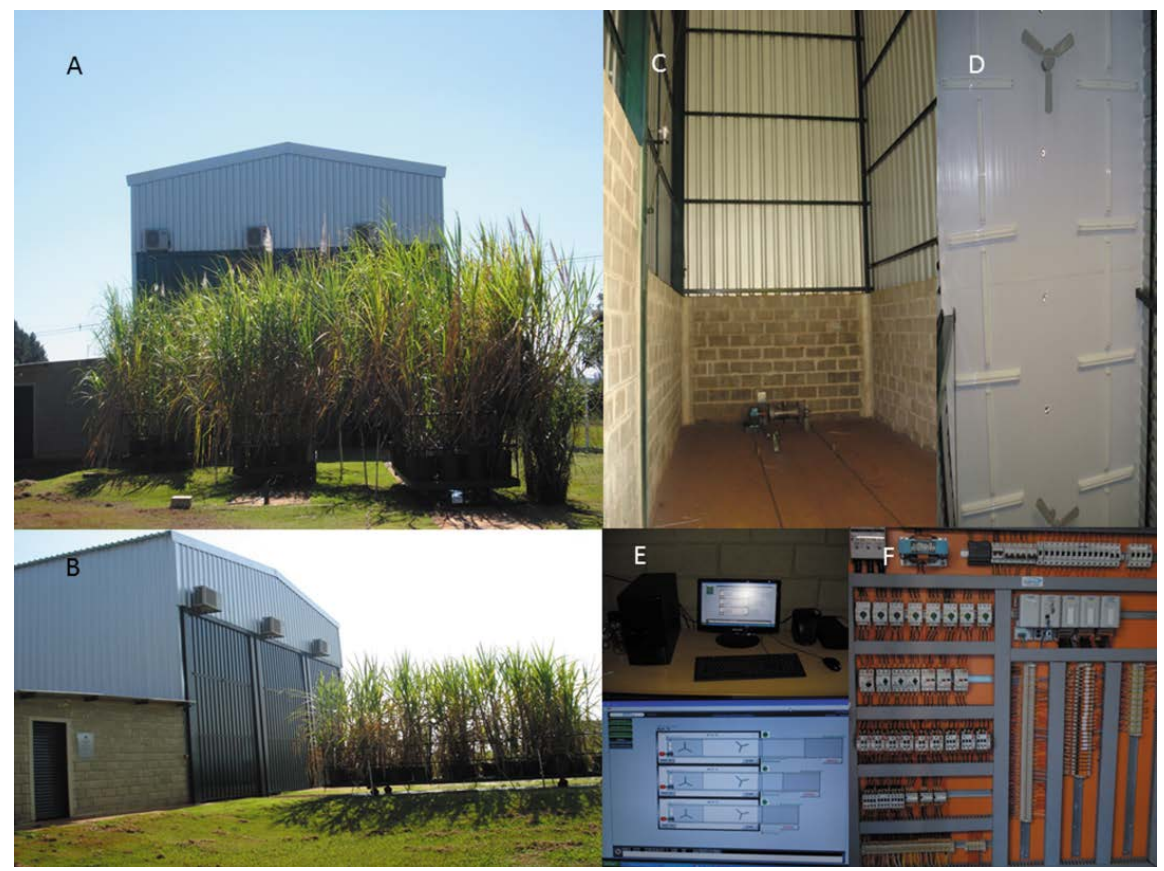

Figure 1. Photoperiod facility. A-External view with the mobile wagons; B—Photoperiod chambers; C-Internal chamber; D-Light structure in the celling; E-Automation Software; F-Automation painel.

\subsection{Flowering Induction}

The treatments were $30 \mathrm{~s}$ (Treatment I), $45 \mathrm{~s}$ (Treatment II) and 1 min (Treatment III) of a decrease in the daily photoperiod, starting from $12 \mathrm{~h} 55 \mathrm{~min}$ ([8] [9]) and continuing until the end of the experiment. The irradiation was controlled in a photoperiod facility by a combination of incandescent and fluorescent light bulbs programmed to switch on/switch off to simulate sunrise and sunset, respectively, with the option of a daily reduction in the photoperiod.

The opening and closing of the photoperiod chamber gates and the movement of the wagons was controlled automatically according to the programmed period of light and external temperature. The temperature was controlled in the range of $21^{\circ} \mathrm{C}-32^{\circ} \mathrm{C}$, with an internal optimum control at $27^{\circ} \mathrm{C}$ for the three treatments. To achieve this, reversible air conditioners (hot/cold) were installed in each photoperiod chamber, and devices that detect temperature were placed both inside and outside of the photoperiod chamber. The automation of the photoperiod chamber allowed the identification of the optimal conditions for induction and flowering.

The induction began in September 2010, and daily evaluations were performed until the end of April 2011. During the induction period, all of the morphological changes that indicate flowering, such as elongation and the date of flag leaf emergence were recorded as also the date of panicle emergence. In the period of inflorescence emergence, the relative humidity was maintained above $80 \%$ (to simulate an intense period of rain).

The inflorescences were harvest to test the pollen viability under the artificial flower induction. Mature anthers were mixed with iodine $0.1 \mathrm{~N}$ solution to visualise the percentage of blue pollen grains in relation to the total stained pollen grains in a microscope slide ([11]). The inflorescences received a score ranging from 1 (female or 
pollen receptor) to 9 (male or pollen donor) based on the number of blue stained pollen grains ([11]) (Table 2).

\section{Results}

The first sign of flower induction which is characteristic of the Saccharum species, i.e., plant elongation, was observed at 60 days after the beginning of the flower induction treatment, indicating that the genotypes responded to the treatments. Among the tillers of the same genotype, in Treatments I (30 s) and II (45 s), some were etiolated leading to a visual lack of uniformity compared to treatment III (1 min).

Overall, the period of flag leaf emission was 110 to 179 days from the beginning of induction, and the emergence of inflorescences occurred at 137 to 207 days after the beginning of induction (Table 3) for all of the treatments.

Table 2. Pollen viability scores according to the percentage of
blue stained pollen (\%) using 0.1 N iodine method.
\begin{tabular}{cc}
\hline Percentage of blue pollens (\%) & Score \\
\hline 0 & 9 \\
1 to 9 & 8 \\
10 to 19 & 7 \\
20 to 40 & 6 \\
41 to 60 & 4 \\
61 to 80 & 3 \\
81 to 99 & 2 \\
100 & 1 \\
\hline
\end{tabular}

Table 3. Number of days of artificial photoperiod induction until leaf flag and inflorescence emission for 16 sugarcane genotypes at three different treatments.

\begin{tabular}{|c|c|c|c|c|c|c|c|c|c|c|c|c|c|c|c|c|c|c|}
\hline \multicolumn{19}{|c|}{ Days of induction } \\
\hline \multicolumn{10}{|c|}{ Flag leaf emission } & \multicolumn{9}{|c|}{ Inflorescence emission } \\
\hline \multirow{3}{*}{ Genotypes } & \multirow{2}{*}{\multicolumn{3}{|c|}{$\begin{array}{c}\text { Treatment I } \\
\text { Tillers }\end{array}$}} & \multirow{2}{*}{\multicolumn{3}{|c|}{$\begin{array}{c}\text { Treatment II } \\
\text { Tillers }\end{array}$}} & \multicolumn{3}{|c|}{ Treatment III } & \multicolumn{3}{|c|}{ Treatment I } & \multicolumn{3}{|c|}{ Treatment II } & \multicolumn{3}{|c|}{ Treatment III } \\
\hline & & & & & & & & Tillers & & & Tiller & & & Tiller & & & Tillers & \\
\hline & 1 & 2 & 3 & 1 & 2 & 3 & 1 & 2 & 3 & 1 & 2 & 3 & 1 & 2 & 3 & 1 & 2 & 3 \\
\hline IACSP94-2101 & 154 & & & & & & & & & & & & & & & & & \\
\hline IACSP93-2060 & 144 & & & & & & 179 & 179 & & & & & & & & & & \\
\hline IACSP96-7569 & 117 & 134 & & 155 & & & 139 & 140 & & 154 & 159 & & 159 & & & 177 & & \\
\hline SP80-1842 & & & & 139 & 150 & 152 & & & & & & & 159 & 175 & & & & \\
\hline SP89-1115 & 117 & 119 & 132 & 116 & 132 & & & & & 154 & 172 & & 193 & 154 & & & & \\
\hline RB86-7515 & & & & 146 & 149 & & & & & & & & & & & & & \\
\hline IACSP00-8095 & 139 & 148 & & & & & & & & 154 & 165 & & & & & & & \\
\hline IACSP00-8206 & 124 & 147 & & 144 & 145 & & & & & & & & 186 & 190 & & & & \\
\hline CTC12 & 139 & & & 116 & 117 & 117 & & & & 174 & & & 137 & 141 & 148 & & & \\
\hline СТC8 & 117 & 118 & 151 & 110 & 110 & 111 & & & & 140 & 146 & 192 & 140 & 146 & 152 & & & \\
\hline CTC6 & & & & 168 & 172 & & & & & & & & & & & & & \\
\hline CTC15 & 144 & 149 & & & & & & & & & & & & & & & & \\
\hline IACSP97-2055 & 140 & 151 & & & & & & & & & & & & & & & & \\
\hline IACSP95-5094 & 140 & 142 & 142 & 133 & 144 & 153 & 152 & 157 & & 182 & 159 & 173 & 192 & & & 198 & 207 & \\
\hline SP90-1638 & & & & 139 & & & & & & & & & 193 & & & & & \\
\hline CO213 & & & & 133 & & & & & & & & & 154 & & & & & \\
\hline
\end{tabular}


The first genotype to emit the flag leaf was CTC8 (at 110 days after induction) while the first genotype to emit an inflorescence was CTC12 (at 137 days after induction), both in treatment II (45 s). However, not all of the genotypes that produced a flag leaf also emitted an inflorescence. Moreover, flag leaf production did not occur for all of the tillers in each pot. The genotypes with all the three tillers exhibiting signs of induction (a flag leaf) were SP80-1842 (Treatment II), SP89-1115 (Treatment I), CTC12 (Treatment II), CTC8 (Treatment I and II) and IACSP95-5094 (Treatment I and II) (Table 3).

Irrespective of the treatments evaluated all the tillers of the genotypes IACSP00-8095, CTC12, CTC8, SP901638 and Co213 produced an inflorescence (Table 3). In contrast, the number of genotypes that emitted a flag leaf was different among the treatments. Eleven genotypes emitted a flag leaf in Treatments I and II, whereas only three genotypes emitted a flag leaf in Treatment III. In addition, there was a difference in the number of genotypes that emitted an inflorescence among treatments, respectively of 6, 9 and 2 for Treatments I, II and III. Therefore, not all of the sugarcane genotypes that emitted a flag leaf in a particular treatment also emitted an inflorescence (Table 3). The genotypes IACSP00-8095, SP801842 and IACSP00-8206 exclusively flowered in treatment (I) while Co213 in Treatment II.

In general, the number of days either for a flag leaf or inflorescence emission was different for the tillers within the same genotype (Table 3). The time between flag leaf emission and inflorescence emission of the 16 sugarcane genotypes are presented in Table 4. The IACSP96-7569 genotype exhibited the shortest time (4 days) between flag leaf emission and flowering, in Treatment II. Conversely, the SP89-1115 genotype required the longest time interval (77 days) to emit an inflorescence in Treatment II. It was note that, although the time between the flag leaf emergence and flowering did not vary among the sugarcane genotypes, the same was not observed among the tillers within the treatments (Table 4).

The emergence of an inflorescence alone is not the only important factor in crosses as pollen viability also has to be considered. The pollen viability scores (ranging from 1 to 9) are presented in Table 5 . The pollen viability scores indicated that some inflorescences behaved as female (pollen receptor) while others behaved as male

Table 4. Time in days to inflorescence emission from the flag leaf emission of 16 sugarcane genotypes under flower induction conditions.

\begin{tabular}{|c|c|c|c|c|c|c|c|c|c|}
\hline \multicolumn{10}{|c|}{ Days of induction } \\
\hline \multicolumn{10}{|c|}{ Emission of inflorescence from the flag leaf } \\
\hline \multirow{3}{*}{ Genotypes } & \multicolumn{3}{|c|}{ Treatment I } & \multicolumn{3}{|c|}{ Treatment II } & \multicolumn{3}{|c|}{ Treatment III } \\
\hline & \multicolumn{3}{|c|}{ Tillers } & \multicolumn{3}{|c|}{ Tillers } & \multicolumn{3}{|c|}{ Tillers } \\
\hline & 1 & 2 & 3 & 1 & 2 & 3 & 1 & 2 & 3 \\
\hline \multicolumn{10}{|l|}{ IACSP94-2101 } \\
\hline \multicolumn{10}{|l|}{ IACSP93-2060 } \\
\hline IACSP96-7569 & 37 & 25 & & 4 & & & 38 & & \\
\hline SP801842 & & & & 20 & 25 & & & & \\
\hline SP891115 & 37 & 53 & & 77 & 22 & & & & \\
\hline \multicolumn{10}{|l|}{ RB867515 } \\
\hline IACSP00-8095 & 15 & 17 & & & & & & & \\
\hline IACSP00-8206 & & & & 42 & 45 & & & & \\
\hline CTC12 & 35 & & & 21 & 24 & 31 & & & \\
\hline СТС8 & 23 & 28 & 41 & 30 & 36 & 41 & & & \\
\hline \multicolumn{10}{|l|}{ CTC6 } \\
\hline \multicolumn{10}{|l|}{ CTC15 } \\
\hline \multicolumn{10}{|l|}{ IACSP97-2055 } \\
\hline IACSP95-5094 & 42 & 17 & 31 & 59 & & & 46 & 50 & \\
\hline SP901638 & & & & 54 & & & & & \\
\hline $\mathrm{CO} 213$ & & & & 21 & & & & & \\
\hline
\end{tabular}


Table 5. Pollen viability scores of the sugarcane genotypes that emitted inflorescences at flower induction condition.

\begin{tabular}{|c|c|c|c|c|c|c|c|c|c|}
\hline \multicolumn{10}{|c|}{ Pollen viability scores (1 - 9) } \\
\hline \multirow{3}{*}{ Genotypes } & \multicolumn{3}{|c|}{ Treatment I } & \multicolumn{3}{|c|}{ Treatment II } & \multicolumn{3}{|c|}{ Treatment III } \\
\hline & \multicolumn{3}{|c|}{ Tillers } & \multicolumn{3}{|c|}{ Tillers } & \multicolumn{3}{|c|}{ Tillers } \\
\hline & 1 & 2 & 3 & 1 & 2 & 3 & 1 & 2 & 3 \\
\hline \multicolumn{10}{|l|}{ IACSP94-2101 } \\
\hline \multicolumn{10}{|l|}{ IACSP93-2060 } \\
\hline IACSP96-7569 & 4 & 6 & & 4 & & & 4 & & \\
\hline SP801842 & & & & 1 & 1 & & & & \\
\hline SP891115 & 8 & 9 & & 8 & 8 & & & & \\
\hline \multicolumn{10}{|l|}{ RB867515 } \\
\hline IACSP00-8095 & 2 & 2 & & & & & & & \\
\hline IACSP00-8206 & & & & 4 & 4 & & & & \\
\hline CTC12 & 2 & & & 3 & 3 & 3 & & & \\
\hline СТC8 & 1 & 1 & 2 & 1 & 2 & 2 & & & \\
\hline \multicolumn{10}{|l|}{ CTC6 } \\
\hline \multicolumn{10}{|l|}{ CTC15 } \\
\hline \multicolumn{10}{|l|}{ IACSP97-2055 } \\
\hline IACSP95-5094 & 2 & 2 & 2 & 3 & & & 2 & 2 & \\
\hline SP901638 & & & & 2 & & & & & \\
\hline CO213 & & & & 2 & & & & & \\
\hline
\end{tabular}

(pollen donor). The SP80-1842 (Treatment II), IACSP00-8095 (Treatment I), CTC12 (Treatment I), CTC8 (treatments I and II), IACSP95-5094 (treatments I and III), SP90-1638 (Treatment II) and Co213 (Treatment II) genotypes showed high pollen viability scores (scores of 1 and 2).

Some genotypes showed intermediate pollen viability scores (3 and 4) and could either be used as pollen donors or be emasculated to receive pollen. Such scores were observed for genotypes IACSP96-7569 (Treatments I, II and III), IACSP00-8206 (Treatment II), CTC12 (Treatment II) and IACSP95-5094 (Treatment II).

The genotypes with low viability scores $(6,7,8$, and 9), thus considered as pollen receptors due to their low probability of selfing were IACSP96-7569 (Treatment I) and SP89-1115 (Treatments I and II).

Overall, the genotypes did not show great variation in the pollen viability scores in the different treatments and among the tillers of the same genotype. Moreover, the genotypes presented similar scores when exposed to different treatments, even at non equal flowering times.

\section{Discussion}

Flowering is essential to any breeding programme to promote crosses. Floral induction is usually observed prior to panicle emergence through stalk elongation, lateral sprouting and flag leaf emission. The stalk size increases when the day length ranged between $12 \mathrm{~h} 55$ to $11 \mathrm{~h} 30$ which occurs during the inductive photoperiod ([5] [8]).

The non-uniformity among the tillers observed within the same pots from Treatments I and II was probably due to elongation. In fact, most of the induction occurred in the first two treatments whereas the fewest induced plants were observed in Treatment III.

It was important to highlight that the induction period occurred during an unusual time, when the natural photoperiod increased which was the opposite condition required for sugarcane flower induction. Nevertheless, induction and flower emergence were achieved, overall advancing flowering by approximately 90 days compared to natural conditions. Moreover, the decreasing photoperiod treatments adopted in other countries were also successful for the Brazilian genotypes, in addition to the management of the factors that drive flowering. Indeed, the management of the factors that govern flowering can enable breeders to obtain flowers at any period of the year, thus promoting flowering synchronism and allowing a better planning of desired crosses. 
In fact, the emission of flag leaves is an indication that sugarcane is induced to flower, once it is a visible phase that precedes flower emission. However, according to our daily observations, the emission of a flag leaf does not predict the date of flowering. Many of the genotypes that early emitted a flag leaf not necessarily flowered before the latter ones ([12]). In addition, even in the same genotype under different treatments, the time between flag leaf emergence and flowering was different, indicating that the photoperiod can influence flowering during this stage.

One of the difficulties found in our work was the balance between induction and flowering of the genotypes within and among the treatments. This point deserves further studies with an increase in the number of replicates and treatments. It is well known that different varieties behave differently in relation to the number of days required within the inductive period for floral stimulation ([13]), and the amount of floral stimulation required can lead to panicle differentiation at the beginning or end of the induction period.

A non-uniformity of flowering is also observed in commercial sugarcane plantations, where induced varieties can emit inflorescences, all in the same period or by stages. Indeed, this situation is due to the inflorescence classification according to the flowering intensity by sugarcane genetic breeding programmes. The lack of flowering uniformity can be addressed to the physiological age of the stalks, which may be more uniform or non-uniform, depending on the genotype. Therefore, although the planting of the genotypes occurred at the same time, it is possible that the tillers of each genotype were at different physiological ages, thus leading to induction at different times. This situation could be minimised by the use of tubettes with one bud each, which would guarantee stalks of the same physiological age and also an increase in the number of replicates.

The fact that some genotypes flowered in more than one treatment does not necessarily indicate that one treatment is better than the other, as the flowering events occurred on different dates, which can facilitate the choice of a genotype for crossing. With the use of the photoperiod chambers, it was possible either to obtain inflorescences or viable pollen, thus allowing future sugarcane crosses at Ribeirão Preto, which is a region considered unsuitable for natural crosses [14]. These results were clearly due to the temperature and moisture uniformity of the three treatments, in agreement with the uniformity of the pollen viability scores derived from the tillers from the same genotype among and within the treatments.

The scores uniformity of the pollen viability is probably associated with the genotype, as all of the genotypes remained under the same conditions of humidity and temperature, with only the photoperiod being variable. In fact, some breeders have observed that the amount of viable pollen produced can vary among genotypes. Moreover, once the inflorescences are classified as pollen receptors (female) or pollen donors (male), the classification rarely changes from one hybridisation campaign to another. However, the temperature range of $21^{\circ} \mathrm{C}$ to $32^{\circ} \mathrm{C}$ and relative humidity greater than $80 \%$ may not be adequate for all genotypes. Thus further studies are required to verify the possibility of an inflorescence classified as female can become a donor with the management of the temperature and humidity. According to the literature, sugarcane pollen viability, in general, is maintained at $21^{\circ} \mathrm{C}$ to $32^{\circ} \mathrm{C}$ and $67 \%$ humidity ([15]); however, a lack of information related to differences among sugarcane genotypes remains.

The use of a photoperiod facility provides suitable artificial conditions to flowering and pollen viability of several sugarcane genotypes. Therefore, such photoperiod facility constitutes a valuable tool to understanding flowering physiology and also to synchronise flowering in introgression genetic programmes. Although the production of a flag leaf precedes flowering, the emergence of a flag leaf is not indicative of when the genotype will emit an inflorescence.

\section{Acknowledgements}

The present research was financed by Fundação de Amparo a Pesquisa do Estado de São Paulo FAPESP/BIOEN 2008/56146-5) and IAC (Instituto Agronômico de Campinas). M.L.M. receive Master fellowship from CAPES.

\section{References}

[1] Clements, H.F. and Awada, M. (1967) Experiments on the Artificial Induction of Flowering in Sugarcane. International Society of Sugar Cane Technologists, 12, 795-812.

[2] Humbert, R.P. (1974) El cultivo de la caña de azucar. 6th Edition, Editorial Continental, México DF.

[3] Srivastava, R.P., Singh, S.E., Singh, P. and Singh, S.B. (2006) Artificial Induction of Flowering in Sugarcane under Sub-Tropical Conditions-A Successful Approach. Sugartech, 8, 184-186.

[4] Taiz, L. and Zeiger, E. (2010) Plant Physiology. 6th Edition, Sinauer Associates, Sunderland. 
[5] Berding, N. (1981) Improved Flowering and Pollen Fertility in Sugarcane under Increased Night Temperature. Crop Science, 21, 863-867. http://dx.doi.org/10.2135/cropsci1981.0011183X002100060016x

[6] Berding, N., Pendrigh, R.S. and Dunne, V. (2007) Can Flowering in Sugarcane Be Optimized by Use of Differential Declinations for the Initiation and Developmental Phases? Proceedings of International Society of Sugarcane Technologists, Durban, 699-711.

[7] Pereira, A.R. (1985) Previsão do florescimento em cana-de-açúcar. Comunicação da Pesquisa Agropecuária, 3, 15-16.

[8] Berding, N. (1995) Improving Flowering through Breeding: Progress and Prospects. International Society of Sugar Cane Technologists, 17, 162-171.

[9] Moore, P.H. and Nuss, K.J. (1987) Flowering and Flower Synchronization. In: Heinz, D.J., Ed., Sugarcane Improvement through Breeding, Elsevier, Amsterdam, 273-311. http://dx.doi.org/10.1016/B978-0-444-42769-4.50012-6

[10] Scarpari, M.S., Garcia, J.C., Xavier, M.A., Landell, M.G.A., Mendonca, J.R. and Melloni, M.L.G. (2011) Building and Automation of the First Photoperiod Facility Made in Brazil for Sugarcane Breeding. Proceedings of the 10th Germplasm and Breeding 7th Molecular Biology Workshop, Maceió, 39-39.

[11] Machado Jr., G.P. (1987) Melhoramento da cana-de-açúcar. In: Paranhos, S.B., Ed., Cana-de-açúcar: Cultivo e utilização, Fundação Cargill , Campinas, 165-186.

[12] Berding, N., Pendrigh, R.S. and Dunne, V. (2010) Pursuing Higher Efficacy for Managed Photoperiodic Initiation of Sugarcane Flowering in the Tropics. Proceedings of Australia Society of Sugar Cane Technologists, Bundaberg, 234250.

[13] Berding, N. and Hurney, A.P. (2005) Flowering and Lodging, Physiological-Based Traits Affecting Cane and Sugar Yield. What Do We Know of Their Control Mechanisms and How Do We Manage Them? Field Crops Research, 92, 261-275. http://dx.doi.org/10.1016/j.fcr.2005.01.015

[14] Melloni, M.L.G., Scarpari, M.S., Pinto, L.R., Perecin, D., Xavier, M.A. and Landell, M.G.A. (2014) Selfing Rate Estimation in Sugarcane under Unfavorable Natural Conditions of Crossing by Using Microsatellite Markers. Genetics and Molecular Research, 13, 2278-2289. http://dx.doi.org/10.4238/2014.March.31.8

[15] Moore, P.H. (1987) Physiology and Control of Flowering. Proceedings of Copersucar International Sugarcane Breeding Workshop, Piracicaba, 101-127. 
Scientific Research Publishing (SCIRP) is one of the largest Open Access journal publishers. It is currently publishing more than 200 open access, online, peer-reviewed journals covering a wide range of academic disciplines. SCIRP serves the worldwide academic communities and contributes to the progress and application of science with its publication.

Other selected journals from SCIRP are listed as below. Submit your manuscript to us via either submit@scirp.org or Online Submission Portal.
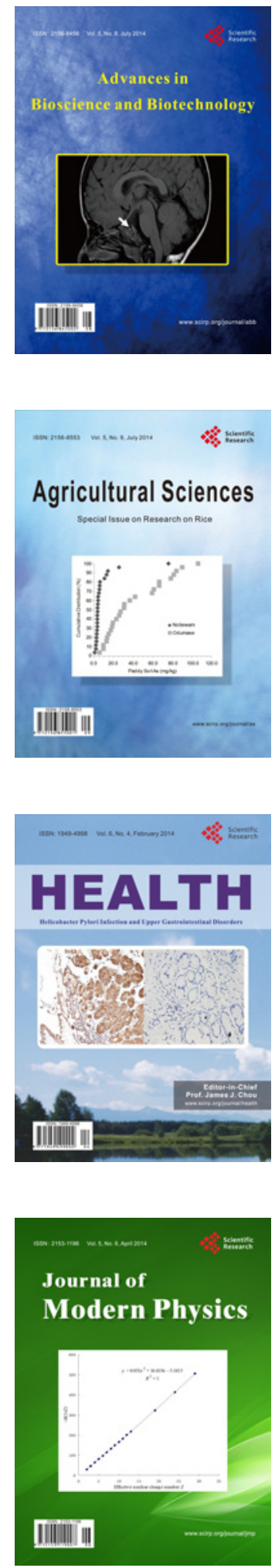
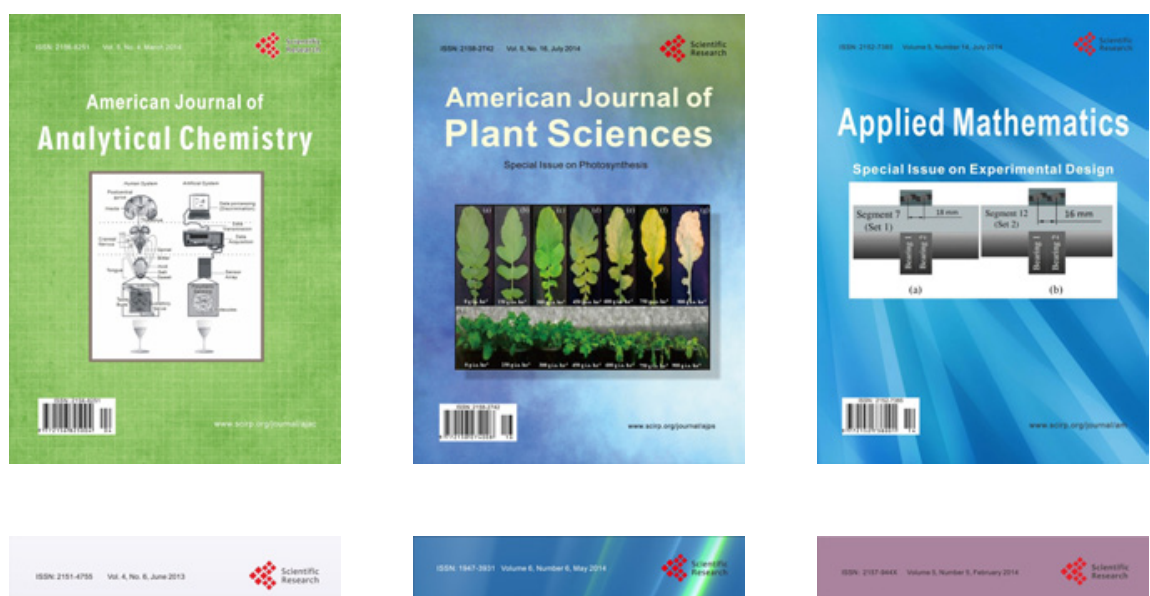

Creative Education
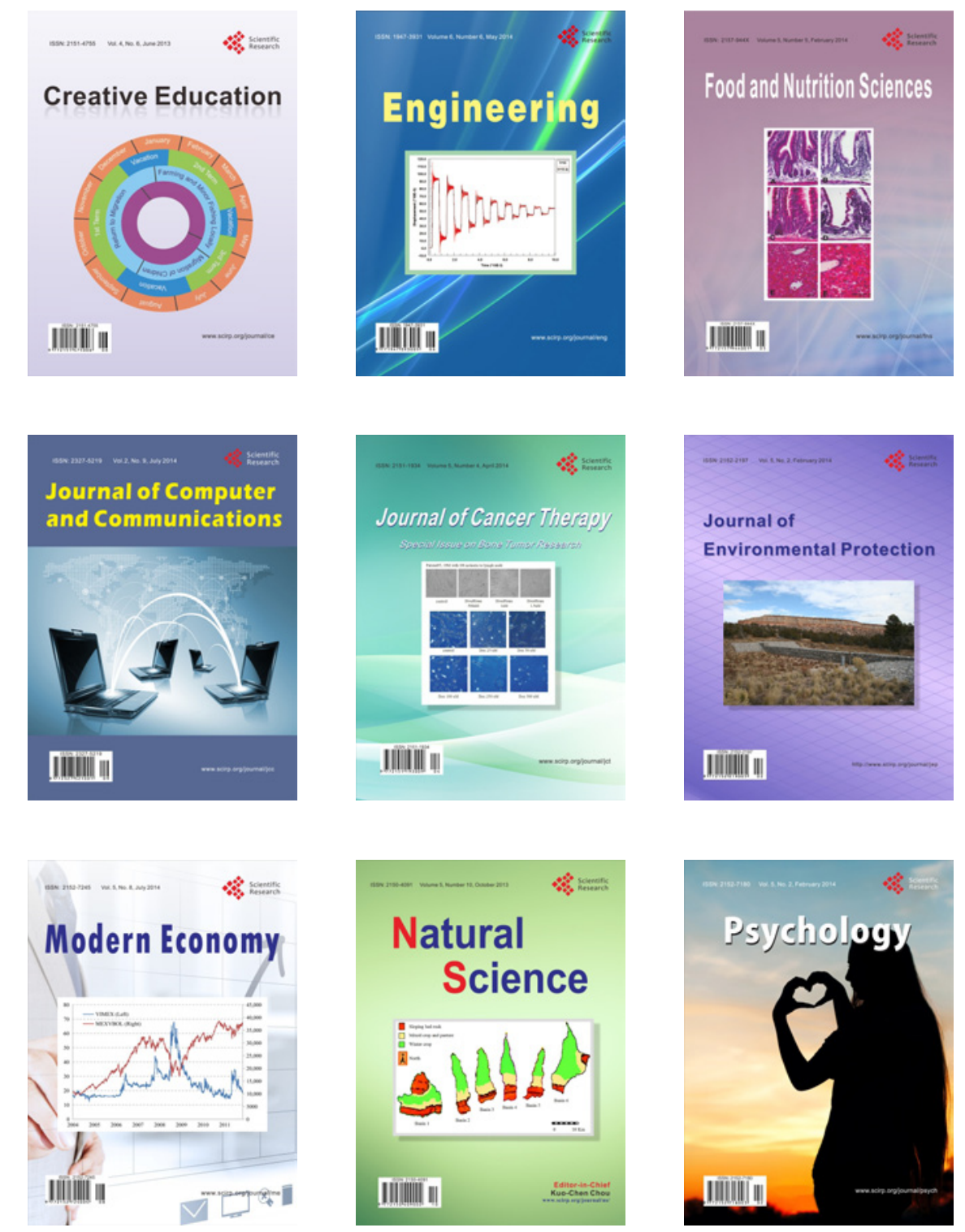